\title{
BMJ Open Scoping review: bladder cancer in Nigeria - what are the gaps in clinical care and research?
}

\author{
Abdulkarim Muhammad lya, ${ }^{1}$ Katharina Beyer (D) , ${ }^{2}$ Pinky Kotecha, ${ }^{2}$ \\ Joyce Kibaru (1D , ${ }^{2}$ Muzzammil Abdullahi, ${ }^{1,3}$ Sani Usman Alhassan, ${ }^{1}$ \\ Muhammad Inuwa Mustapha, ${ }^{4}$ Abdullahi Ahmad, ${ }^{5}$ Yusuf Lawal, ${ }^{6}$ \\ Jalo Rabiu Ibrahim, ${ }^{7}$ Aliyu Aminu, ${ }^{8}$ Aisha Abubakar, ${ }^{9}$ Abdullahi Saleh, ${ }^{10}$ \\ Richard T Bryan, ${ }^{11}$ Mieke Van Hemelrijck (1) , ${ }^{2}$ Beth Russell (i) ${ }^{2}$
}

To cite: lya AM, Beyer K, Kotecha P, et al. Scoping review: bladder cancer in Nigeria what are the gaps in clinical care and research? BMJ Open 2022;12:e049241. doi:10.1136/ bmjopen-2021-049241

- Prepublication history and additional supplemental material for this paper are available online. To view these files, please visit the journal online (http://dx.doi.org/10.1136/ bmjopen-2021-049241).

Received 20 January 2021 Accepted 10 February 2022
Check for updates

(C) Author(s) (or their employer(s)) 2022. Re-use permitted under CC BY-NC. No commercial re-use. See rights and permissions. Published by BMJ.

For numbered affiliations see end of article.

Correspondence to

Beth Russell;

beth.russell@kcl.ac.uk

\section{ABSTRACT}

Objectives There are currently no national guidelines regarding bladder cancer treatment and clinical care pathways in Nigeria. The aim of this scoping review was to identify any gaps in the knowledge of epidemiology, clinical care and translational research in order to aid the development of a defined clinical care pathway and guide future research.

Methods A scoping review was conducted by searching Medline, Ovid Gateway, The Cochrane library and Open Grey literature using predefined search terms from date of inception to June 2020. Studies were included if they discussed the epidemiology or treatment pathway of bladder cancer. All data were charted and were analysed in a descriptive manner. A consultation phase was also conducted consisting of a multidisciplinary team of clinicians and bladder cancer survivors.

Results A total of 19 studies were deemed suitable for inclusion. The themes included the epidemiology of bladder cancer (high prevalence of schistosomiasis), research surrounding the biology of the disease and translational research including potential biomarkers. The consultation phase highlighted some possible sociocultural and infrastructural issues relating to both the diagnosis and treatment of bladder cancer, with poor knowledge of bladder cancer and its symptoms within the general population identified as a key issue.

Conclusion Even though the factors surrounding the relationship between schistosomiasis and the histopathology of bladder cancer remain unclear, there is potential for screening for schistosomiasis in endemic regions of sub-Saharan Africa. Other key areas for future research include the dissemination of information to the general population surrounding bladder cancer and its symptoms to encourage prompt diagnosis.

\section{INTRODUCTION}

Being the 10th most common cancer globally, bladder cancer (BC) accounts for $3 \%$ of all new cancer cases and $2 \%$ of all cancer mortalities. ${ }^{1}$ The incidence is rising in Africa, with the highest rates recorded in North Africa. The incidence in North Africa and sub-Saharan
Strengths and limitations of this study

- Grey literature was included as well as indexed journal articles to allow for the collation of data from a variety of sources.

- A consultation phase consisting of a multidisciplinary group of clinicians as well as two bladder cancer survivors was included in the review.

- It is possible that some relevant studies were not accessible on the search engines used for this review, and so some studies may have been overlooked.

- However, our search strategy was methodically developed and several databases were accessed and so we consider this to be unlikely.

Africa have been reported, respectively, as 10.1 and 5.0 per 100000 for males and 2.0 and 1.5 per 100000 for females. BC ranks 7 th overall (2nd in males and 11th in females) in Nigeria. $^{2}$

The stage groupings of non-muscle-invasive (NMIBC) and muscle invasive (MIBC) are accepted descriptors of BC in developed countries, with $75 \%-80 \%$ of new cases categorised as the former category and $20 \%-25 \%$ as the latter. ${ }^{3}$ BC can also be classified into two main groups: urothelial and non-urothelial. ${ }^{4}$ In developed countries, urothelial carcinoma or transitional cell carcinoma (TCC) is the predominant histological subtype of $\mathrm{BC},{ }^{56}$ comprising around $90 \%$ of all BC cases. ${ }^{6}$ Risk factors for TCC include smoking ${ }^{7}$ and exposure to chemicals in the dye industry. ${ }^{8}$ As it usually presents at an early stage without detrusor muscle involvement (NMIBC), it is associated with a good prognosis. ${ }^{9}$

However, in low/middle-income countries, such as those within the Middle East and parts of Africa, squamous cell carcinoma (SCC), which is the most common variant of non-urothelial carcinoma, is often 
more prevalent than TCC. SCC itself has two main subtypes: schistosomiasis(Bilharzia)-associated and nonschistosomiasis-associated SCC, although it is important to note these do not differ morphologically. In the Middle East and parts of Africa where Schistosoma haematobium infection is endemic, schistosomiasis-associated SCC is most common. SCC is a more aggressive disease with a poorer prognosis when compared with TCC. ${ }^{10}$ In Northern Nigeria, SCC is the most frequent subtype of $\mathrm{BC}$ representing $53 \%$ of cases despite the lower prevalence of schistosomiasis in Northern Nigeria. ${ }^{11-13}$ Meanwhile, in Southern Nigeria, it has been reported that around $20 \%$ of BCs were SCC with a higher prevalence of schistosomiasis than in the north. ${ }^{14} 15$ This highlights the possible role of a yet to be identified environmental and/ or genetic factor(s), explaining the disparity in histologic type between the northern and southern part of the country.

With a paucity of published evidence relating to the epidemiology, clinical treatment and translational research into BC in Nigeria, this scoping review aims to identify gaps in clinical care and research on $\mathrm{BC}$ in Nigeria.

\section{METHODS}

Our methodology for this scoping review was developed based on the Joanna Briggs Institute guidelines ${ }^{16}$ and, more specifically, the framework developed by Arksey and O'Malley. ${ }^{17}$ Unlike other reviews such as systematic reviews which tend to address a precise research question, a scoping review can be used to map and summarise available evidence on a particular subject. ${ }^{16}$ They can be conducted for a variety of reasons. This current scoping review was conducted with the aim of identifying the types of available evidence on BC research in Nigeria, with the overall aim of identifying knowledge gaps in this area. Preferred Reporting Items for Systematic Reviews and Meta-Analyses-Scoping Reviews extension for scoping reviews ${ }^{18}$ were followed to ensure all suggested items were reported. A detailed protocol of this scoping review has been published previously ${ }^{19}$ and a brief summary is presented in figure 1 .

The following research question was developed in consultation with the research and clinical teams:

'What is known about the epidemiology and treatment pathway of BC in Nigeria?'. Medline (using the PubMed interface), Ovid Gateway (Embase and Ovid) (search terms available in online supplemental file 1), The Cochrane library and Open Grey literature were searched for relevant studies between June and July 2020. A separate search for grey literature was conducted by the team in Nigeria through National Postgraduate Medical College of Nigeria, West African College of Surgeons (WACS) and Nigerian Association of Urological Surgeons (NAUS). In addition, verbal communication with most of the tertiary health institutions was instigated to determine the existence of institutional-based protocols.

All types of study design were considered for inclusion if they assessed the themes of prevention, diagnosis, treatment, survivorship or translational research regarding BC in Nigeria. All published studies (excluding grey literature) underwent a critical appraisal using the Joanna Briggs Institute critical appraisal forms (online supplemental file 2). ${ }^{16}$ Two independent reviewers charted the data, and the studies identified were analysed using a qualitative method. The studies were split into several subthemes: prevalence, prevention, diagnosis, treatment, survivorship and translational research/biology.

\section{RESULTS}

A total of 76 records were identified through database searching after removing duplicates (figure 2). After screening by title and abstracts, 46 full texts were assessed for eligibility. In total, 19 studies were deemed suitable for inclusion. Of the 19 studies included, 3 were identified through the grey literature search. Initially, the search identified 16 grey literature including six dissertations,

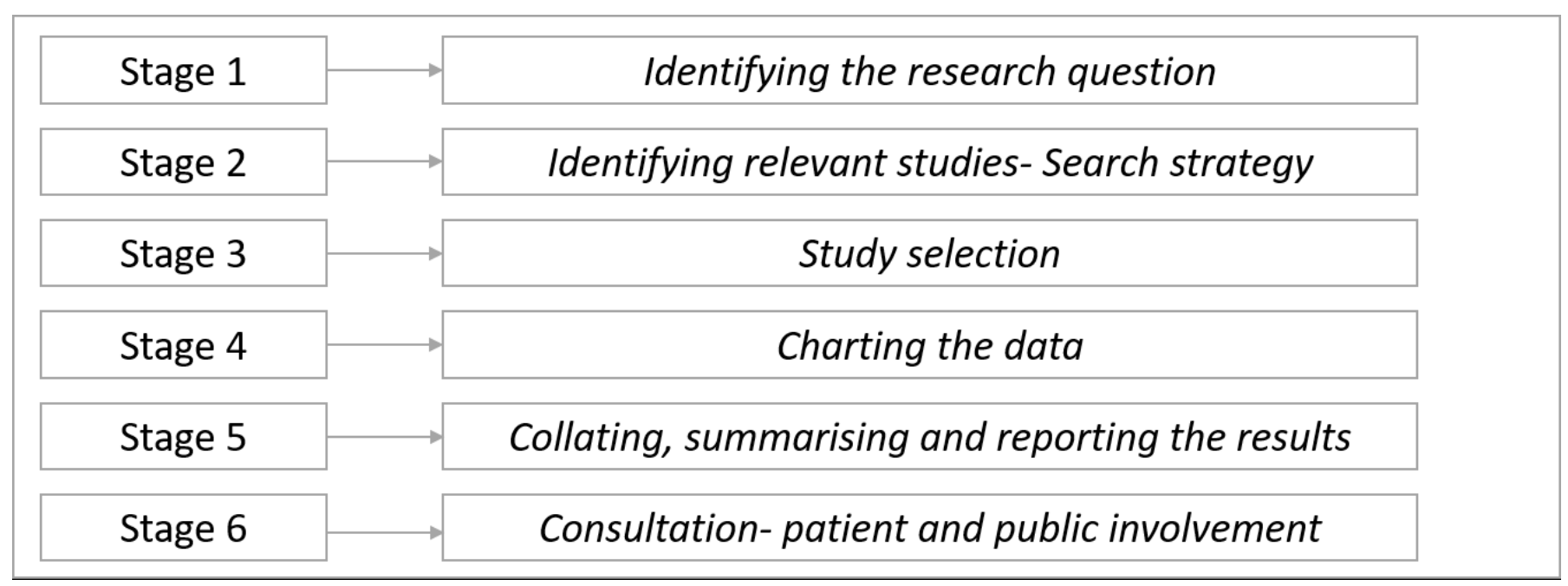

Figure 1 Stages of scoping review. 


\section{PRISMA 2009 Flow Diagram}

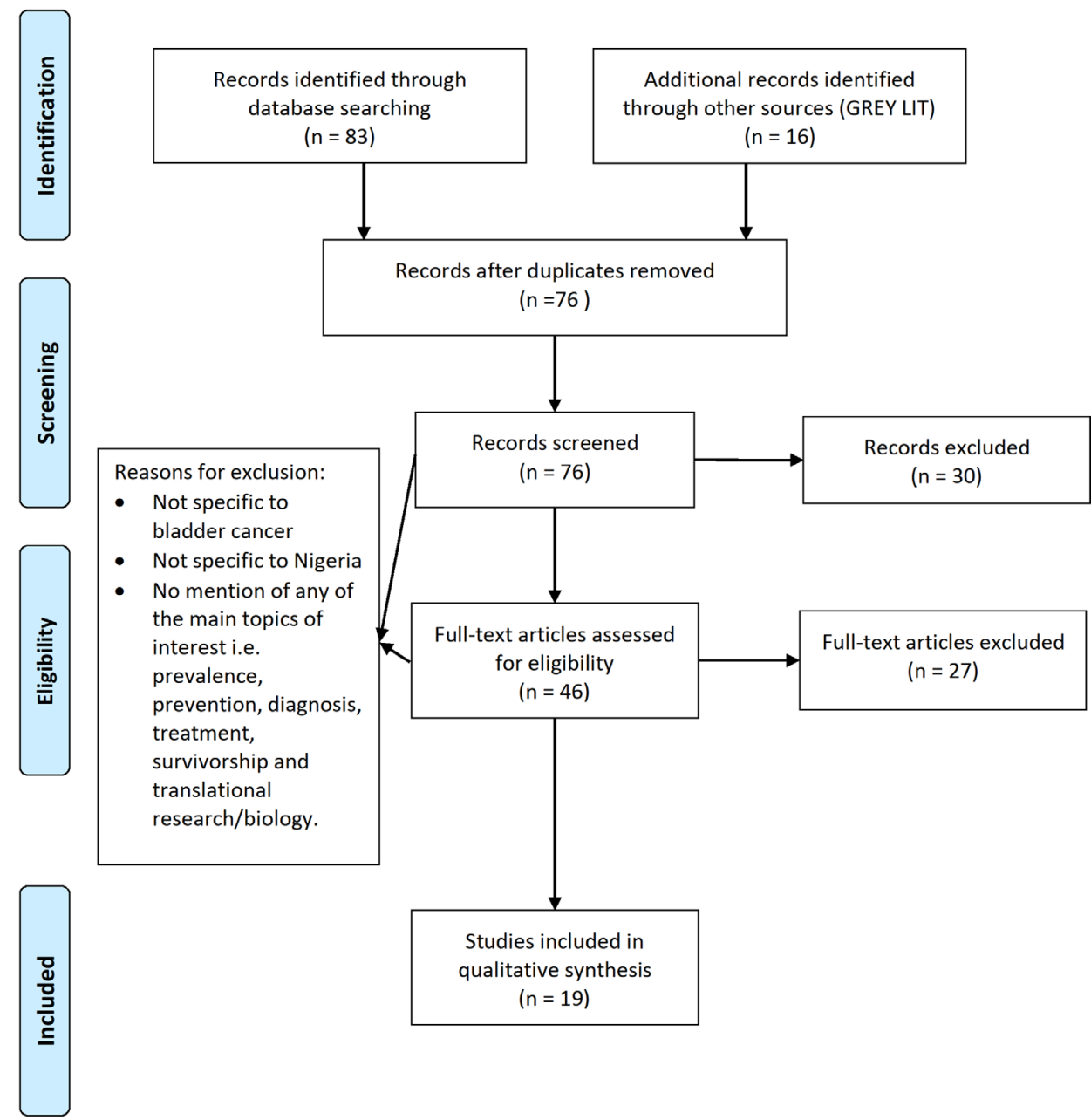

From: Moher D, Liberati A, Tetzlaff J, Altman DG, The PRISMA Group (2009). Preferred Reporting /tems for Systematic Reviews and MetaAnalyses: The PRISMA Statement. PLoS Med 6(7): e1000097. doi:10.1371/journal.pmed1000097

For more information, visit www.prisma-statement.org.

Figure 2 PRISMA flow chart. PRISMA, Preferred Reporting Items for Systematic Reviews and Meta-Analyses.

8 conference abstracts and 2 local audits. Thirteen were subsequently excluded during the screening process.

Six studies described the prevalence of $\mathrm{BC}$ within the various regions of Nigeria and each listed the prevalence of TCC versus SCC $^{12-1420-22}$ (tables 1 and 2 and online supplemental file 3 ). The case series by Ochicha et $a l^{12}$ and Yunusa et $a l^{22}$ presented the characteristics of $\mathrm{BC}$ patients in Kano (northwest), while the results from Mungadi and Malami ${ }^{13}$ were from Sokoto, also in the northwest. In Kano, the prevalence of TCC was reported to be $35 \%$ vs $53 \%$ for SCC according to Ochicha et al, ${ }^{12}$ and $44 \%$ SCC vs $29 \%$ TCC in the audit by Yunusa et al. ${ }^{22}$ Similarly, Mungadi and Malami stated that the majority (65\%) of BC patients had SCC. ${ }^{13}$ Both studies mentioned that there was a strong association between the endemic areas of schistosomiasis and SCC. Meanwhile and $\mathrm{Mbonu}^{20}$ and Takure et $a l^{14}$ described the prevalence of BC types in Enugu (southeast) and Ibadan (southwest), respectively. The study by Aghaji et al stated that 56\% had TCC and $39 \%$ had SCC, while Takure et al concluded that $69 \%$ of BC patients had TCC and 20\% had SCC.

A common theme among the studies was the need to control the infection of $S$. haematobium for the prevention of $\mathrm{BC}^{1323-25}$ (tables 1 and 2). The study by Umar $e t a l^{25}$ recommended the implementation of the WHO's mass treatment if the infection of Schistosoma haematobium infection is above $50 \%$ within a local authority. Ossai $e t$ $a l^{23}$ observed a high prevalence of bacteriuria and urinary schistosomiasis in primary school children, which consequently could portend an increased risk of $\mathrm{BC}$ in the 


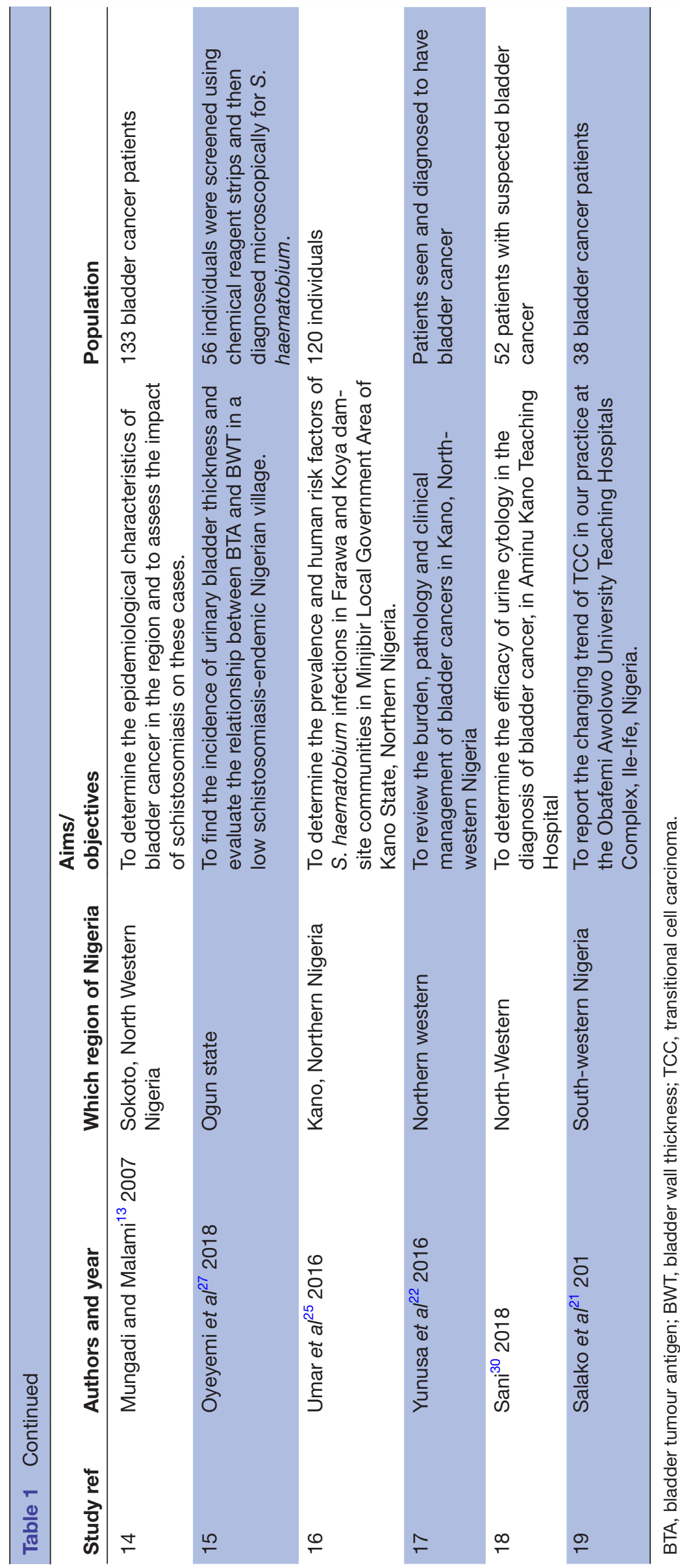

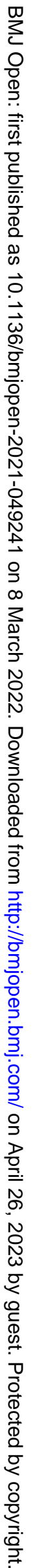


Table 2 Identified research gaps and policy recommendations

\begin{tabular}{clll}
\hline $\begin{array}{l}\text { Study } \\
\text { ref }\end{array}$ & Authors & Theme & Type of recommendation \\
\hline 1 & Ossai et $\left.a\right|^{23}$ & Prevention & Policy \\
\hline 2 & Oyeyemi et a ( $^{26}$ & $\begin{array}{l}\text { Translational/ } \\
\text { biology }\end{array}$ & Research and policy \\
\hline
\end{tabular}

Research gaps/recommendation for actions

- There is a need for intensive health education to sensitise the people on the risk of urinary schistosomiasis and its co-infection with bacteriuria.

- This could be done through community dialogue

- Need for a study with larger sample size and possibly aflatoxin exposure analysis by serum AF-alb rather than urinary aflatoxin M1 (AFM1) or even a combination of both biomarkers to validate initial this observation of the study.

- Study on the role of schistosomiasis in bladder cancer through biomonitoring of human BTA.

- Community education of rural agrarian households on best practices to mitigate mycotoxin exposure in farm produce.

\begin{tabular}{|c|c|c|c|c|}
\hline 3 & Bakare et $\mathrm{a}^{33}$ & $\begin{array}{l}\text { Translational/ } \\
\text { biology }\end{array}$ & Research & $\begin{array}{l}\text { Need for a study with larger } \\
\text { sample size to study association of } \\
\text { schistosomiasis and arsenicosis with } \\
\text { bladder pathologies. }\end{array}$ \\
\hline 4 & Ochicha et $\mathrm{al}^{12}$ & Prevalence & $\mathrm{N} / \mathrm{A}$ & $\mathrm{N} / \mathrm{A}$ \\
\hline 5 & Aghaji et $a^{20}$ & Prevalence & Research and policy & $\begin{array}{l}\text { Improve education and diagnostic } \\
\text { techniques } \\
\text { Improve therapeutic facilities to } \\
\text { reduce morbidity and mortality rates } \\
\text { will fall. } \\
\text { Understand impact of socioeconomic } \\
\text { status (SES) on presentation }\end{array}$ \\
\hline 6 & Onile et $\left.a\right|^{24}$ & $\begin{array}{l}\text { Translational/ } \\
\text { biology/ } \\
\text { prevention }\end{array}$ & Research & $\begin{array}{l}\text { Further research on the determinants } \\
\text { and progress of the bladder } \\
\text { pathologies in Schistosoma } \\
\text { haematobium infected Nigerian } \\
\text { adults. }\end{array}$ \\
\hline 7 & Muhammad et al ${ }^{29}$ & $\begin{array}{l}\text { Diagnosis and } \\
\text { translational }\end{array}$ & N/A & $\begin{array}{l}\text { Review the cut-off (of } 54 \mu / \mathrm{mL} \text { ) for } \\
\text { BTA in the Sokoto region to increase } \\
\text { the specificity of the marker for the } \\
\text { diagnosis of bladder cancer }\end{array}$ \\
\hline 8 & Takure et $a l^{14}$ & Prevalence & Policy & $\begin{array}{l}\text { Train relevant health professionals to } \\
\text { enable them to diagnose and treat } \\
\text { bladder cancer in its early stages and } \\
\text { thus reduce the high morbidity and } \\
\text { mortality associated with advanced } \\
\text { disease. }\end{array}$ \\
\hline 9 & Ikuerowo et al ${ }^{31}$ & Treatment & N/A & $\mathrm{N} / \mathrm{A}$ \\
\hline 10 & Shu'aibu et $a l^{32}$ & Treatment & $N / A$ & $N / A$ \\
\hline 11 & Onile et $\mathrm{al}^{28}$ & $\begin{array}{l}\text { Translational/ } \\
\text { biology/ } \\
\text { diagnosis }\end{array}$ & Research & $\begin{array}{l}\text { Need for validation of biomarkers in a } \\
\text { large sample size }\end{array}$ \\
\hline 12 & Akinwale et a $\left.\right|^{34}$ & Biology & Research & $\begin{array}{l}\text { Improve follow-up of these patients } \\
\text { using cystoscopy rather than cytology }\end{array}$ \\
\hline
\end{tabular}




\begin{tabular}{|c|c|c|c|c|}
\hline $\begin{array}{l}\text { Study } \\
\text { ref }\end{array}$ & Authors & Theme & Type of recommendation & $\begin{array}{l}\text { Research gaps/recommendation for } \\
\text { actions }\end{array}$ \\
\hline 14 & Mungadi and Malami ${ }^{13}$ & $\begin{array}{l}\text { Prevention and } \\
\text { prevalence }\end{array}$ & $\mathrm{N} / \mathrm{A}$ & $\mathrm{N} / \mathrm{A}$ \\
\hline 15 & Oyeyemi et $a l^{27}$ & Diagnosis & Research & $\begin{array}{l}\text { The role of urogenital schistosomiasis } \\
\text { in urinary BTA levels needs to be } \\
\text { further explored. }\end{array}$ \\
\hline 16 & Umar et $\left.a\right|^{25}$ & Prevention & Policy & $\begin{array}{l}\text { Implementation of WHO's } \\
\text { recommendation for mass treatment } \\
\text { of the whole community if infection of } \\
\text { S. haematobium infection is }>50 \% \text { by } \\
\text { the local authorities. } \\
\text { Screening of the community for } \\
\text { bladder pathology by ultrasonography } \\
\text { is strongly recommended to assess } \\
\text { the risk of development of vesical } \\
\text { cancer in aged individuals. }\end{array}$ \\
\hline 17 & Yunusa et $a l^{22}$ & $\begin{array}{l}\text { Prevention, } \\
\text { diagnosis, } \\
\text { treatment and } \\
\text { survival }\end{array}$ & Research and policy & $\begin{array}{l}\text { Community based studies to get the } \\
\text { exact prevalence. } \\
\text { More effort in prevention of } \\
\text { schistosomiasis at all levels } \\
\text { Encourage patient to present } \\
\text { with early disease through health } \\
\text { education. } \\
\text { Screening to detect early disease and } \\
\text { surveillance for people with history of } \\
\text { childhood haematuria. } \\
\text { Better facilities for cystoscopy and } \\
\text { biopsy and other tumour markers }\end{array}$ \\
\hline 19 & Salako et $a^{21}$ & Prevalence & $\mathrm{N} / \mathrm{A}$ & $\mathrm{N} / \mathrm{A}$ \\
\hline
\end{tabular}

BTA, bladder tumour antigen; N/A, not available.

future. The authors recommended for all primary school children to be screened and treated for bacteriuria.

With respect to the diagnosis of $\mathrm{BC}$ and/or schistosomiasis, five studies investigated potential biomarkers and/ or the use of urine cytology $y^{26-30}$ (tables 1 and 2). The two studies by Oyeyemi et al looked at the association between bladder tumour antigen (BTA) with other factors. The first of the studies, looked at whether BTA levels were associated with aflatoxin exposure (a fungal metabolite) in Nigerian villagers. ${ }^{26}$ The study concluded a null result with no evidence of a link between aflatoxin exposure and BTA. The second study by the same group of authors, 
investigated the relationship between BTA and bladder wall thickness (BWT) in a low schistosomiasis-endemic Nigerian village. ${ }^{27}$ They reported no association between BWT and BTA and lower urinary tract symptoms, and suggested that the role of urogenital schistosomiasis in urinary BTA levels needed to be explored further. Meanwhile, the study by Muhammad et al looked at the role of a quantitative test (BTA TRAK) compared with urine cytology in the diagnosis of $\mathrm{BC}$ in the schistosoma endemic area of Sokoto. ${ }^{29}$ The authors concluded that BTA TRAK is less specific than urine cytology, but is more sensitive for detecting BC in the area of investigation. The study by Onile $e t$ al differed in that they identified several parasite-specific and host-specific protein biomarkers for the detection of schistosomiasis. ${ }^{28}$ The dissertation, which was identified as part of the grey literature search, was submitted to the WACS as part of the requirements for the award of fellowship of the college in surgery. This dissertation aimed to assess the efficacy of urine cytology in the diagnosis of $\mathrm{BC}$ and deemed the use of urine cytology as an effective way of diagnosing patients who present with features indicative of $\mathrm{BC} .{ }^{30}$

Two case series reported their experiences of patients undergoing radical cystectomy with different urinary diversion techniques ${ }^{31}{ }^{32}$ (table 1). The first by Ikuerowo et al looked at the outcome of a Mainz II pouch urinary diversion in radical cystectomy patients. ${ }^{31}$ They concluded that over the 10-year period investigated, 11 patients underwent a Mainz II pouch urinary diversion and overall the technique was deemed safe with good long-term results. The second by Shu'aibu et al report their experience of patients who underwent radical cystectomy with a W-ileal pouch construction over a 5 -year period. ${ }^{32}$ Six patients underwent the procedure, of which only one patient remained alive 5 years after surgery (although two were lost to follow-up). The authors described the technique as a complex procedure requiring highly experienced surgeons and surgical team.

In terms of the biological effects surrounding schistosomiasis, three studies each looked at how this was related to arsenicosis, ${ }^{33}$ bladder pathology ${ }^{24}$ and urothelial hyperplasia $^{34}$ (tables 1 and 2). Bakare et alstated that Arsenicosis was a public health concern for the study population of Eggua, situated in South-West Nigeria and that the prevalence of schistosomiasis was $21 \% .^{33}$ Notwithstanding, there was no association between bladder pathology and arsenicosis or between schistosomiasis associated-bladder pathology and arsenicosis. Also conducted in Eggua, the study by Onile et al involved the screening of 257 adults for $S$. haematobium infection and associated bladder pathologies. ${ }^{24}$ The prevalence of $S$. haematobium infection was found to be $26 \%$ and bladder pathologies were observed in $34 \%$ of participants. ${ }^{24}$ A large proportion of the patients with bladder pathology also had existing schistosomiasis infection ( $85 \%$ ). The study by Akinwale $e t$ $a l$ involved participants from Imala Odo which is also an area within South-West Nigeria. ${ }^{34}$ The 780 strong community has no basic infrastructure and is made up of migrant fishing families. The authors observed severely dysplastic malignant squamous cells among a few normal squamous cells in three patients (out of 32). They subsequently state that their results support a Kenyan study which showed an association between urinary tract hyperplasia and $S$. haematobium infection. ${ }^{35}$

The consultation phase included discussion between two consultant urologists, a urology senior registrar, a consultant oncologist, a consultant pathologist, a consultant interventional radiologist, a consultant public health physician, a consultant clinical microbiologist, an oncology pharmacist, a cancer nurse specialist and two $\mathrm{BC}$ survivors. The topics of epidemiology, the clinical care pathway and translational research were discussed. There was a general consensus that, although schistosomiasis was endemic in certain areas, this did not always reflect the proportion of SCC versus TCC observed. The clinicians discussed a missing link in this association which was yet to be identified but proposed access to fresh water as a possible cause. In terms of the clinical care pathway, there was an absence of a national standardised pathway. Instead, hospitals would implement local pathways based on personal experiences. The clinicians therefore recommended the development of national guidelines and pathways. Translational research was identified as a rarity in most areas of Nigeria with infrastructure and funding being the main two hindering factors. There was much discussion around the potential benefits of a biobank and better use of the already existing national data registry which at present only captures diagnostic information. The clinicians also spoke about the reluctance by some patients to accept treatments particularly, those that are injectable.

Both of the patient representatives were males of retirement age with no previous family history of BC. They did, however, have very different experiences in terms of their diagnosis and cancer care. Patient A had to undergo seven different hospital visits before undergoing transurethral resection of bladder tumour. Patient B also had initial difficulties in getting access to care, but was financially able to opt for treatment at an alternative hospital for radical cystectomy. The patients spoke about the general lack of awareness of BC in Nigeria and, although neither one refused treatment, patient A decided to also take traditional herbal medicines alongside his medical treatment.

\section{DISCUSSION}

The most commonly studied topic was the prevalence of SCC and TCC and its link with schistosomiasis. Despite there being a lack of clarity behind the link between the histopathology of $\mathrm{BC}$ and schistosomiasis, it was clear from the review that schistosomiasis is a major problem in Nigeria and there are strong links surrounding an increased risk of BC of any type. Several studies investigated potential biomarkers for BC such as BTA. There was, however, a paucity of studies discussing the clinical 
pathways for BC patients in Nigeria. The consultation phase re-iterated many points found in the research articles, including a lack of national guidelines or protocols for the treatment of $\mathrm{BC}$ patients.

The results of this review, including the consultation phase with a multidisciplinary group of professionals and patient representatives, have highlighted numerous key issues for which several recommendations are outlined below.

\section{Epidemiology}

As presented in this review, there is disparity between the incidence of TCC and SCC in different regions of Nigeria. Despite schistosomiasis being more prevalent in the southern regions of the country, ${ }^{15}$ there is not always a clear correlation between schistosomiasis and SCC prevalence, with TCC ever becoming the most common histology nationwide. The studies identified within this scoping review did not investigate this important area of research, but did confirm the higher prevalence of TCC in the south. ${ }^{1420}$ More studies are therefore needed to investigate the factors underlying the link between schistosomiasis and SCC vs TCC prevalence. Another factor which may be important to consider also is tobacco smoking which is a known risk factor for both SCC and TCC. ${ }^{36}{ }^{37}$ Future studies in this area could include ecological analyses to evaluate and incidence of BC types as well as Schistosoma over time.

The prevention and mass treatment of schistosomiasis was investigated within four of the studies from this review; therefore, this area of research is not as neglected as others. Umar et al recommended for the utilisation of mass treatment, as suggested by the $\mathrm{WHO}^{25}$; however, it is important to note that despite mass drug administration to curb the infection rates, there still remains a lack of transmission control and provision of good water supply which has meant the mortality from the infection has not decreased significantly. ${ }^{38}$

\section{Clinical care pathways}

None of the studies identified within this review investigated the clinical care pathways for $\mathrm{BC}$ patients in Nigeria, although two did present case series of radical cystectomy patients undergoing different urinary diversion techniques. Interestingly, the study by Shu'aibu et $a l,{ }^{32}$ which investigated the outcomes of patients undergoing an W-ileal pouch urinary diversion, lost two of their six patients during follow-up; this issue emerged during the consultation phase whereby it was suggested that contact with patients post-treatment can be challenging. No other treatment modalities (eg, intravesical therapy, radiotherapy) were mentioned within the literature identified within this scoping review.

At present, the NAUS only have guidelines available for the treatment of prostate cancer patients. Nevertheless, as highlighted during the consultation phase of this review, despite a paucity of national guidelines regarding the treatment pathway for BC patients in Nigeria, this does not mean that patients receive suboptimal care by their treating physicians. Many hospitals, in particular tertiary centres, have developed their own sets of guidelines based on previous experiences; other centres may refer to or adapt existing national/international guidelines that already exist. However, there is still a call for the inauguration of national guidelines to ensure standardisation and continuity of care across the country, and this is a topic worthy of specific future studies.

A topic which was raised during the consultation phase of this review was the lack of communication between the clinical and pharmaceutical aspects of patients' care. For example, the availability of drugs can at times be an issue and can lead to delays in treatment. A recommendation in this area would be for clinical and pharmaceutical departments to collaborate more closely so as to better coordinate the clinical needs for patients within the resources available.

It was highlighted during the consultation phase that the majority of BC patients in Nigeria present at an advanced disease stage and that this is reflected by poor survival statistics (though we do not have data to quantify this). Patients are often of low financial means and from rural areas with insufficient or no medical insurance. A fundamental concern is how to improve this scenario and raise awareness of $\mathrm{BC}$ and its symptoms. Hence, patient education is vital and, as highlighted by patient representatives during the consultation phase, knowledge of symptoms and disease risk factors could prompt patients to seek clinical help sooner. Such an awareness campaign has existed for breast cancer in Nigeria and has proved to be effective. ${ }^{39}$ Furthermore, non-invasive diagnostic techniques (such as ultrasonography) could be implemented to limit the numbers of patients discouraged in seeking medical consultation by the perception of cystoscopy. In addition, there needs to be a focus on the early diagnosis of patients. As a result of patients being diagnosed in a timely manner, it is hoped this will then allow for the well-being of BC survivors to be investigated. This area of research was lacking in the studies identified within this review and is therefore a recommended area for future research.

\section{Translational research}

It was evident from this review that some research had been undertaken surrounding the link between biomarkers and other factors. Two studies, by the same group of authors, looked at the link between BTA and BWT and aflatoxin, with no association identified. BTATRAK is a US Food and Drug Administration (FDA) approved immuneassay for the monitoring of $\mathrm{BC}$ recurrence when used in conjunction with cystoscopy. ${ }^{40}$ It has been noted, however, that while BTA assays have higher sensitivity than urine cytology, the specificity is lower therefore leading to more false-positives. ${ }^{40}$ This is an important factor to consider when BTA is being used as a surrogate for BC pathology (as reported by Oyeyemi $e t$ $\left.a l^{26}\right)$. 
The BC patients in Nigeria are often from high risk groups such as farmers and fishermen, who are exposed to bodies of water infected with S. haematobium. Many patients also have a cultural belief that injectable medicines are harmful and therefore often abscond from treatment. This is particularly difficult for the treating clinician when many beneficial drugs (eg, cytotoxic chemotherapy) are administered intravenously. Therefore, for these patients, education is key. A possible solution would be the adoption of cancer support groups or cancer charities which focus on patients' needs and wellbeing. These groups can be an excellent source of education and emotional support for patients, particularly for those without a stable domestic support system.

Further to the gaps in research highlighted by this review, there is also a challenge in identifying enough clinicians and/or academics to conduct the necessary future research, as well as the enabling of resources and infrastructure. Translational research within a laboratory setting can be a costly affair and usually requires funding through research grants. A future recommendation in this area could be the set-up of local or regional biobanks in order to store tumour specimens for research purposes, although establishing such an infrastructure should be considered in the context of the other priorities outline above.

\section{Strengths and limitations}

This review aimed to identify the gaps in clinical care and research for BC in Nigeria as part of the development of a larger national research programme, an endeavour which has not previously been undertaken. We anticipated that there would be a limited number of studies on the subject of interest, and so included grey literature as well as indexed journal articles to allow for the collation of data from a variety of sources. Another strength was the inclusion of a consultation phase with a multidisciplinary group of clinicians as well as two BC survivors. This process gave invaluable information on a personal level which would not have been achieved from the literature alone. We utilised the Joanna Briggs Institute critical appraisal tools to determine whether to include studies in the review. In this case, all studies were deemed suitable for inclusion. It is possible that some relevant studies were not accessible on the search engines used for this review, and so some studies may have been overlooked. However, our search strategy was methodically developed and several databases were accessed and so we consider this to be unlikely.

\section{CONCLUSION}

This scoping review has identified several themes regarding the epidemiology and clinical care pathways of BC patients in Nigeria which require further research and development. Despite the existing knowledge of the link between schistosomiasis and SCC, this review highlighted that the correlation between these two diseases is not always clear and can differ between regions. Therefore, the investigation of factors affecting the prevalence of SCC vs TCC and its relationship with $S$. haematobium infection is just one research area requiring attention. There is also a need for both national and hospital guidelines for BC care in Nigeria. Further recommendations include the need to better educate the general population regarding $\mathrm{BC}$ and its symptoms to improve early diagnosis. It is hoped that the results and recommendations from this scoping review can pave the way for the development of BC guidelines within Nigeria as well as guiding future research.

\section{Author affiliations}

${ }^{1}$ Urology Unit, Aminu Kano Teaching Hospital, Kano, Nigeria

${ }^{2}$ Translational Oncology and Urology Research, King's College London, London, UK

${ }^{3}$ Urology, Bayero University College of Health Sciences, Kano, Nigeria

${ }^{4}$ Oncology Unit, Radiology Department, Aminu Kano Teaching Hospital, Kano, Nigeria

${ }^{5}$ Pathology, Aminu Kano Teaching Hospital, Kano, Nigeria

${ }^{6}$ Radiology Department, Aminu Kano Teaching Hospital, Kano, Nigeria

${ }^{7}$ Community Medicine, Aminu Kano Teaching Hospital, Kano, Nigeria

${ }^{8}$ Microbiology, Aminu Kano Teaching Hospital, Kano, Nigeria

${ }^{9}$ Pharmacy, Aminu Kano Teaching Hospital, Kano, Nigeria

${ }^{10}$ Nursing department, Aminu Kano Teaching Hospital, Kano, Nigeria

${ }^{11}$ Bladder Cancer Research Centre, Institute of Cancer \& Genomic Sciences,

University of Birmingham, Birmingham, UK

Twitter Katharina Beyer @beyer_katharina and Muhammad Inuwa Mustapha @ mohdimustapha

Acknowledgements The authors gratefully acknowledge the invaluable comments from the clinicians and patient representative who took part in the consultation phase of this review.

Contributors Conceptualisation and planning: AMI, KB, PK, JK, MA, SUA, MIM, AAh YL, JRI, AAm, AAb, AS, RTB, MVH and BR. Study design: AMI, PK, JK, RTB, MVH and BR. Acquisition of data: AMI, PK, JK and BR. Conduct: AMI, KB, PK, JK, MA, SUA, MIM, AAh, YL, JRI, AAm, AAb, AS, RTB, MVH and BR. Manuscript writing and review: AMI, KB, PK, JK, MA, SUA, MIM, AAh, YL, JRI, AAm, AAb, AS, RTB, MVH and BR. Guarantor: BR

Funding The authors have not declared a specific grant for this research from any funding agency in the public, commercial or not-for-profit sectors.

Competing interests None declared.

Patient consent for publication Not applicable.

Provenance and peer review Not commissioned; externally peer reviewed.

Data availability statement Data sharing not applicable as no datasets generated and/or analysed for this study.

Supplemental material This content has been supplied by the author(s). It has not been vetted by BMJ Publishing Group Limited (BMJ) and may not have been peer-reviewed. Any opinions or recommendations discussed are solely those of the author(s) and are not endorsed by BMJ. BMJ disclaims all liability and responsibility arising from any reliance placed on the content. Where the content includes any translated material, BMJ does not warrant the accuracy and reliability of the translations (including but not limited to local regulations, clinical guidelines, terminology, drug names and drug dosages), and is not responsible for any error and/or omissions arising from translation and adaptation or otherwise.

Open access This is an open access article distributed in accordance with the Creative Commons Attribution Non Commercial (CC BY-NC 4.0) license, which permits others to distribute, remix, adapt, build upon this work non-commercially, and license their derivative works on different terms, provided the original work is properly cited, appropriate credit is given, any changes made indicated, and the use is non-commercial. See: http://creativecommons.org/licenses/by-nc/4.0/.

\section{ORCID iDs}

Katharina Beyer http://orcid.org/0000-0002-8450-8850

Joyce Kibaru http://orcid.org/0000-0002-9356-0810 
Mieke Van Hemelrijck http://orcid.org/0000-0002-7317-0858

Beth Russell http://orcid.org/0000-0001-5640-8425

\section{REFERENCES}

1 GLOBOCAN. Bladder cancer Factsheet, 2018. Available: https:// gco.iarc.fr/today/data/factsheets/cancers/30-Bladder-fact-sheet.pdf [Accessed 03 Mar 2019].

2 Mohammed AZ, Edino ST, Ochicha O, et al. Cancer in Nigeria: a 10-year analysis of the Kano cancer registry. Niger J Med 2008;17:280-4.

3 Babjuk M, Burger M, Compérat EM, et al. European Association of Urology Guidelines on Non-muscle-invasive Bladder Cancer (TaT1 and Carcinoma In Situ) - 2019 Update. Eur Urol 2019;76:639-57.

4 Abdel-Rahman O. Squamous cell carcinoma of the bladder: a seer database analysis. Clin Genitourin Cancer 2017;15:e463-8.

5 Chavan S, Bray F, Lortet-Tieulent J, et al. International variations in bladder cancer incidence and mortality. Eur Urol 2014;66:59-73.

6 Lamm DL, Torti FM. Bladder cancer, 1996. CA Cancer J Clin 1996;46:93-112.

7 Colombel M, Soloway M, Akaza H, et al. Epidemiology, staging, grading, and risk stratification of bladder cancer. European Urology Supplements 2008;7:618-26. doi:10.1016/j.eursup.2008.08.002

8 Case RA, Hosker ME, McDONALD DB, et al. Tumours of the urinary bladder in workmen engaged in the manufacture and use of certain dyestuff intermediates in the British chemical industry. I. The role of aniline, benzidine, alpha-naphthylamine, and beta-naphthylamine. $\mathrm{Br}$ $J$ Ind Med 1954:11:75-104.

9 Bowa K, Mulele C, Kachimba J, et al. A review of bladder cancer in sub-Saharan Africa: a different disease, with a distinct presentation, assessment, and treatment. Ann Afr Med 2018;17:99. doi:10.4103/ aam.aam_48_17

10 Scosyrev E, Yao J, Messing E. Urothelial carcinoma versus squamous cell carcinoma of bladder: is survival different with stage adjustment? Urology 2009;73:822-7. doi:10.1016/j. urology.2008.11.042

11 Global prevalence of STh and schistosomiasis. Available: https:// Ishtm.maps.arcgis.com/apps/webappviewer/index.html?id=2e1b c70731114537a8504e3260b6fbc0 [Accessed 03 Jun 2020].

12 Ochicha O, Alhassan S, Mohammed AZ, et al. Bladder cancer in Kano--a histopathological review. West Afr J Med 2003;22:202-4.

13 Mungadi IA, Malami SA. Urinary bladder cancer and schistosomiasis in north-western Nigeria. West Afr J Med 2007;26:226-9.

14 Takure AO, Odubanjo MO, Adebayo SA, et al. Histopathologic pattern of bladder cancers in Ibadan Southwest Nigeria: an update. J West Afr Coll Surg 2015;5:17-42.

15 Ezeh CO, Onyekwelu KC, Akinwale OP, et al. Urinary schistosomiasis in Nigeria: a 50 year review of prevalence, distribution and disease burden. Parasite 2019;26:19.

16 Peters M, Godfrey C, Mclnerney P. Chapter 11: Scoping Reviews (2020 version). In: Joanna Briggs Institute Reviewer's Manual, 2020. https://reviewersmanual.joannabriggs.org

17 Arksey H, O'Malley L. Scoping studies: towards a methodological framework. Int J Soc Res Methodol 2005;8:19-32. doi:10.1080/1364557032000119616

18 Tricco AC, Lillie E, Zarin W, et al. PRISMA extension for scoping reviews (PRISMA-ScR): checklist and explanation. Ann Intern Med 2018;169:467-73.

19 Kibaru J, Kotecha P, lya AM, et al. Scoping review protocol: bladder cancer in Nigeria: what are the gaps in clinical care and research? BMJ Open 2021;11:e041894.

20 Aghaji AE, Mbonu OO. Bladder tumours in Enugu, Nigeria. Br J Urol 1989:64:399-402.

21 Salako A, Badmus T, Akinbola T. Changing trend of transitional cell carcinoma of the bladder in Ile-Ife, South Western Nigeria. African Journal of Medicine and Medical Sciences 2019;48 https:// www.researchgate.net/publication/343979633_Changing_trend_ of_transitional_cell_carcinoma_of_the_bladder_in_lle-lfe_South_ Western_Nigeria
22 Yunusa B, Abdullahi M, Mashi A. Bladder cancer burden and challenges of management in Kano. North Western Nigeria 2016 https://www.academia.edu/63015619/Bladder_Cancer_Burden_and_ Challenges_of_Management_in_Kano_North_Western_Nigeria

23 Ossai OP, Dankoli R, Nwodo C, et al. Bacteriuria and urinary schistosomiasis in primary school children in rural communities in Enugu state, Nigeria, 2012. Pan Afr Med J 2014;18 Suppl 1:15.

24 Onile OS, Awobode HO, Oladele VS, et al. Detection of urinary tract pathology in some Schistosoma haematobium infected Nigerian adults. J Trop Med 2016;2016:1-5.

25 Umar M, Umar U, Usman I, et al. Schistosoma haematobium infections: prevalence and morbidity indicators in communities around Wasai dam, Minjibir, Kano state, Northern Nigeria. IJTDH 2016;17:1-8.

26 Oyeyemi O, Ezekiel C, Ayeni K, et al. A pilot biomonitoring study of bladder tumor antigen (BTA) in aflatoxin exposed Nigerian villagers. African Journal of Urology 2018;24:152-6. doi:10.1016/j. afju.2018.02.003

27 Oyeyemi O, Adefalujo A, Ayeni K, et al. Urinary bladder thickness, tumor antigen, and lower urinary tract symptoms in a low Schistosoma haematobium-endemic rural community of Nigeria. Urol Sci 2018;29:151-5.

28 Onile OS, Calder B, Soares NC, et al. Quantitative label-free proteomic analysis of human urine to identify novel candidate protein biomarkers for schistosomiasis. PLoS Negl Trop Dis 2017;11:e0006045-21.

29 Muhammad AS, Mungadi IA, Darlington NN, et al. Effectiveness of bladder tumor antigen quantitative test in the diagnosis of bladder carcinoma in a Schistosoma endemic area. Urol Ann 2019;11:143. doi:10.4103/UA.UA_192_17

30 Sani A. Efficacy of urine cytology in the diagnosis of bladder cancer in Aminu Kano teaching hospital: comparison of cytology and histological findings. West African College of Surgeons $2018 \mathrm{https}$ :// mmed.mosuljournals.com/article_168295_46f99c0c57731e1b2a72 18ef786deeb5.pdf

31 Ikuerowo SO, Ojewuyi OO, Bioku MJ, et al. Outcome of Mainz II pouch urinary diversion after radical cystectomy in patients with muscle-invasive bladder cancer: our experience. Niger J Surg 2018;24:12

32 Shu'aibu S, Liman H, Akpayak I, et al. Preliminary experience with radical cystectomy and w-ileal pouch for muscle invasive transitional cell bladder carcinoma. J West Afr Coll Surg 2012;2:25-37.

33 Bakare SO, Adebayo AS, Awobode HO, et al. Arsenicosis in bladder pathology and schistosomiasis in Eggua, Nigeria. Trans $R$ Soc Trop Med Hyg 2018;112:230-7.

34 Akinwale OP, Oliveira GC, Ajayi MB, et al. Squamous cell abnormalities in exfoliated cells from the urine of Schistosoma haematobium-infected adults in a rural fishing community in Nigeria. World Health Popul 2008;10:18-22.

35 Hodder SL, Mahmoud AA, Sorenson K, et al. Predisposition to urinary tract epithelial metaplasia in Schistosoma haematobium infection. Am J Trop Med Hyg 2000;63:133-8.

36 Manley KV, Hubbard R, Swallow D, et al. Risk factors for development of primary bladder squamous cell carcinoma. Annals 2017;99:155-60.

37 Cumberbatch MGK, Jubber I, Black PC, et al. Epidemiology of bladder cancer: a systematic review and contemporary update of risk factors in 2018. Eur Urol 2018;74:784-95. doi:10.1016/j. eururo.2018.09.001

38 Oyeyemi OT. Schistosomiasis control in Nigeria: moving round the circle? Ann Glob Heal 2020;86:1-3.

39 Salako O, Roberts AA, Isibor VI, et al. Innovative breast cancer awareness and advocacy campaign. J Glob Oncol 2017;3:169-76.

$40 \mathrm{Ng} \mathrm{K}$, Stenzl A, Sharma A, et al. Urinary biomarkers in bladder cancer: a review of the current landscape and future directions. Urol Oncol 2021;39:41-51. doi:10.1016/j.urolonc.2020.08.016

41 Ita OI, Akpayak IC, Onyedibe KI, et al. Strongyloides stercoralis larvae in the urine of a patient with transitional cell carcinoma of the bladder: a case report. J Parasit Dis 2019;43:154-7. doi:10.1007/ s12639-018-1051-6 